\title{
Review of Web Presence of University Libraries of Sri Lanka
}

Wijayaratne, Anusha ${ }^{1}$

\begin{abstract}
The paper discusses the findings of a study that analyze the content and design of university library websites of Sri Lanka and highlights the points that need to be addressed in order to enhance the quality of websites. Besides, this paper presents a simplified version of an evaluative instrument that was developed by the author. Websites of university libraries of Sri Lanka were assessed in terms of both quantitative and qualitative web presence. A 17-itemed evaluative instrument was used to measure the qualitative web presence. The rating of the websites was carried out during the first week of April 2013. Findings revealed that the quantitative web presence of Sri Lankan university libraries is at a quite commendable level. All 3 parameters - availability of websites, size of sites, location of the link to the library site in the parent institution's website - that measured the quantitative web presence were found to be in high level. Besides, out of the two parameters - content richness and design accuracy - that measured qualitative web presence, the content richness level of websites was found to be at a commendable status. However, majority of websites reported low scores when measured in terms of design accuracy. The evaluative instrument presented in this paper would be useful for library professionals in evaluating the current status of the library websites for institutional or research purposes. The evaluative instrument presented in this paper is an original tool and the results generated based on the tool have added a new set of empirical data to the body of literature.
\end{abstract}

Keywords: Library website, Website evaluation studies, Content of library website, Design of library website

\section{Introduction}

The trend of building up libraries in the cyberspace is growing fast exploring new grounds and adding new features. Abundance of studies in the recent literature (i.e. Poll, 2007; Astani \& Elhindi, 2008; Chen, Germain \& Yang, 2009; Manuel \& Walton, 2010; Kaba, 2011;

\footnotetext{
${ }^{1}$ Senior Assistant Librarian, Open University of Sri Lanka, Sri Lanka. Email: idwij@ou.ac.lk
} 
Aharony, 2012; Madhusudhan \& Nagabhushanam, 2012; Vasishta, 2013) that evaluate the library websites in different perspectives is a good indication of the enthusiasm of the librarians around the world towards this fascinating branch of the librarianship. As a result, libraries are now offering $24 / 7$ service; enriched with a wide-spectrum of interactive web-based library services.

An important point that librarians should keep in mind is that websites are in a public domain and can be viewed by people across the borders. Therefore, librarians need to be very careful of what they publish in their websites. Designing and maintaining a site adhering to international standards needs certain commitments from the part of the librarians. Nevertheless, a properly planned maintenance schedule and a periodical redesigning scheme may simplify the process of maintaining a user-centred website.

Standard of the website matters a lot in building up the image of the library and in demonstrating social responsibility. The two main dimensions that determine the standard of a website are the content and design of the site. Both these aspects are equally important for a library website since it aims at serving a range of users including people with special needs.

\subsection{Content of the Website}

Maintaining a comprehensive and up-to-date content is very crucial to achieve the objectives of the site. The main goal of library websites, particularly the websites of educational institutions, is to deliver necessary resources and services to facilitate teaching, learning and research activities. Basically, the content of a library website can be categorized into 4 types namely; resources, services, links and information.

Both resource and service components at libraries have been vastly benefited from the advancement of web technologies. Resources include the subscribed e-resources, open access materials, digitized documents and complied e-resource-products such as webographies. Many traditional library services such as the card catalogue, reference 
service, selective dissemination of information (SDI), document delivery, inter library loan (ILL) etc, have been successfully converted to web formats and deliver via online-real-time and offline modes. The flexibility of these services has allowed the librarians to offer their users with time and place independent service that was only a dream sometime back. The library website also acts as a navigational centre, which gives direct links to numerous sites and resources that visitors may need or find useful to visit while browsing the library site. Librarians can maximize the use of the library website by providing access to external links that their users frequently visit. The information is also a very vital component of a website that needs a lot of attention from the librarian. Information about the in-house services and printed collections; help guides and accessing details on online services and digital resources; about the library; opening hours; library news; messages from the librarian are very decisive for the success of the site. In other words, the library website should be designed as a one-stop shop, which allows users to access a complete coverage of products together with appropriate guidance and instructions.

\subsection{Design of the Website}

An aspect that most librarians seem to be neglecting is the design of the website. Nontechnical librarians think that designing a website is beyond their capability and give the total responsibility to a web developer, most of the time a stranger to the library field. Although, it is not essential for each and every librarian to learn the whole course of web designing, it is very useful if librarians are aware of the basic principles of web designing in order to guide their web developers. The good point is that it is actually easy for anyone from any educational background to learn the fundamental rules of web designing.

\subsubsection{Web accessibility}

Web accessibility, which basically addresses the web access for people with disabilities, is one of the main areas of concern in designing a website. There are several international guidelines such as Web Content Accessibility Guidelines (WCAG) and Section 508 of the Rehabilitation Act of 1973 of USA (http://www.section508.gov/). In addition, there are 
guidelines that are specific for libraries such as International Federation of Library Associations (IFLA) checklist for access to libraries for persons with disabilities (Irvall and Nielsen, 2005) and Elsevier User Centred Design Group guidelines for library websites (Jasek, 2007).

If the website is free from accessibility errors, it brings a lot of value to the website. Several authors (Sloan, 2004; Foley, 2003; Kirkpatrick, 2003; Polanka and O'Gorman, 2001) have pointed out that accessible web design benefits not only the people with disabilities but also the web users as a whole. Besides, authors such as Golub and Lazic (2001) and Kirkpatrick (2003) have stated that application of web accessibility guidelines helps optimizing the site for search engines; simplifying the maintenance process; displaying social responsibility; and reducing legal liabilities. Hence, it is essential for librarians to have a good understanding of principles of accessible web designing and be aware of how to meet them. One of the best tools is the WCAG guidelines developed by the Web Accessibility Initiative (WAI) of the Worldwide Web Consortium (W3C). Summary of WCAG 2.0 Guidelines is given in the Appendix A. The complete WCAG 2.0 can be downloaded from the URL http://www.w3.org/TR/WCAG/. The automatic web tools such as Wave Web accessibility evaluation tool (http://wave.webaim.org) and ACheker (http://achecker.ca/checker), make the life of web developers easier by generating results that highlights the errors on page together with useful comments.

\subsubsection{Hyper Text Markup Language}

Hyper Text Markup Language (HTML) is the most used markup language for creating web pages and other web-based information today. Use of standard HTML codes ensures faster and better view of the website by most web browsers. There are numerous free and open source HTML validation tools, such as W3C Markup Validation Service at http://validator.w3.org and WDG HTML Validator at 
http://www.htmlhelp.com/tools/validator/, that are capable of checking the web documents against formal HTML standards, like those that are published by the Worldwide Web Consortium (W3C).

\subsubsection{Readability}

Readability of the website is a vital accessibility dimension, which measures the ability to understand the content of the site by the target user groups. Besides, it is a critical issue for people with cognitive learning problems.

\subsection{Navigational Mechanism}

Site should have a navigational mechanism that guides the user to find required content elements easily. Without a proper navigational mechanism, users may fail to locate the information or may waste a lot of valuable time in doing so. Besides, user may loose the track while browsing the site, particularly if the site consists of many pages. All these factors may lead to user frustration and dissatisfaction. Consistent use of navigational elements such as site search engines; use of appropriate navigational aids such as "Bread Crumbs" (i.e. return to top, next/previous page in lengthy documents); absence of deadend pages etc. might be very useful to overcome these issues.

\section{Rationale Behind the Study}

The university libraries, which are empowered with highly qualified professional and paraprofessional staff, are the cream of the library sector of the country. Therefore, it is expected them to be proactive and set role models, particularly in adapting modern technological outbreaks. The fast growing field of web technology is one of such innovations that have brought wonders to the librarianship in providing time and place independent service. With the increasing number of users from the net generation and rapid changes in the educational system of the country, going online is not an alternative but is becoming a must for the libraries of all kind. However, Sri Lankan librarians particularly, those who are outside the university sector, seem to be not properly 
equipped to face this challenge. In this regard, university librarians can render a valuable service in empowering the librarians, who are from less equipped institutions and nontechnical backgrounds. Besides, university librarians may contribute immensely towards uplifting the standard of library websites of the country by setting examples through maintaining high standard user centred websites.

Under these circumstances, it is vital to gain a good understanding on strengths and weaknesses of the university library websites to help recognize the rectifying measures to raise the quality of the sites, in order to, set them as benchmarks. However, there are only a handful of recent studies such as Wijayaratne \& Amarasekara, (2011) and Wickramanayake (2012) and that investigated at least a few selected aspects of Sri Lankan academic library websites. This study aims at producing empirical data and revealing areas that need to be addressed in order to enhance the quality of the academic websites of Sri Lanka. In addition, it is also hoped that findings of this study may persuade the librarians to revisit their library websites and carry out necessary corrections and modifications. Above all, the author wishes to open a new dialog on different concerns in designing and maintaining library websites among the Sri Lankan library community.

\section{Objectives of the Study}

The study aims at realizing the following two objectives;

1. Determine the quantitative web presence of Sri Lankan university libraries in terms of 3 parameters namely; availability of websites, size of sites and location of the link to the library site on the parent institution's websites.

2. Determine the qualitative web presence of Sri Lankan university libraries in terms of 2 parameters namely; content richness and design accuracy.

Content richness has been measured in terms of 10 content elements namely; eresources, information about printed resources, web-based services, information about in-house services, useful external links, about the library, library rules, staff information, 
contact information, opening hours. Meanwhile, design accuracy has been measured in terms of 7 design features namely; web accessibility level (WCAG 2.0 success criteria), use of standard HTML codes level, readability level, site search engine, length of the homepage, copyright statement, and last date of update.

\section{Methodology}

\subsection{Method/Procedure}

Websites of university libraries of Sri Lanka were assessed based on an evaluative instrument (see Appendix B). Rating of the websites was carried out by the researcher during the first week of April 2013. Manual inspection and data generated by automatic web tools that were described in the section 4.3.1, were used to rank the measured parameters.

\subsection{Research Instruments}

The following research instruments were used for data collection during this study.

\subsubsection{Evaluative Instrument}

An evaluative instrument, which consists of 10 content elements and 7 design features, was used as the benchmarking tool of assessing library websites. This 17 itemed evaluative instrument is a simplified version of a 140 itemed (i.e. 60 content elements and 80 design features) evaluative instrument that was developed by the author through a 3rounded Delphi study with participation of two international panels of experts. (i.e. Panel I - Content; Panel II - Design). The full version of evaluative tool can be downloaded from the link - http://lib.ou.ac.Ik/images/stories/libstaff/ei\%20anusha2.doc. 


\subsubsection{Automatic web tools}

Three automatic web tools have been used to measure the 3 aspects of web designing namely, web accessibility level (WCAG 2.0 success criteria - Level A), use of standard HTML codes, and readability level.

\subsubsection{AChecker}

The AChecker is an open source accessibility evaluation tool available at http://achecker.ca/checker. This tool allows the user to evaluate a website against several established guidelines including 3 levels (A, AA, AAA) of WCAG 2.0 separately. The WCAG level A, which was taken into consideration in determining the web accessibility of the sites in the present study, denotes the requirements that MUST be satisfied in order to facilitate accessing the web content for disabled users.

\subsubsection{W3C Markup Validation Service}

W3C Markup Validation Service at http://validator.w3.org checks the markup validity of web documents in HTML, XHTML, SMIL, MathML etc. This tool can display the results in various options such as show source, show outline, list message sequentially etc.

\subsubsection{Juicy Studio readability test tool}

Juicy Studio readability test (http://juicystudio.com/services/readability.php) is capable of calculating the readability index score using the Gunning-Fog Index (GFI). Lower the number; more understandable the content is to users, where seventeen is considered as post-graduate level.

\subsection{Population/Sample}

Population of this study is the libraries of national universities of Sri Lanka under the University Grant Commission (UGC). Out of the 15 universities listed in the UGC website (http://www.ugc.ac.lk), 14 of them possess library websites. The websites of the main libraries of those 14 libraries were taken as the sample. See Appendix C 
The library websites of the 'Rajarata University of Sri Lanka' and 'University of the Visual \& Performing Arts' had to be excluded in assessing the qualitative web presence of library websites due to a technical difficulty in measuring those two website using automatic tools. Hence, the total number of websites checked for the qualitative web presence was 12 while all 14 websites were taken into consideration in measuring the quantitative web presence of Sri Lankan University libraries.

\section{Findings}

Key findings of the study are described below parallel to the objectives of the study.

\subsection{Quantitative Web Presence of Libraries}

Out of the 15 universities, 14 of them own a library website. Seven websites are built as a part of their parent institutional website while 7 of them are maintaining separate websites using different templates. The striking factor is that 10 (71\%) library websites consist of over 50 pages. In addition, out of those 10 sites, 3 sites comprise over 100 pages.

The position where the link of the library site appears in the parent institution website is considered as a measurement of visibility of the site. Out of the 14 libraries, 6 (43\%) libraries have a link to their library website on the homepage of parent university website while the link of the 4 library sites appeared in the first level. The links of the rest of the 4 libraries appeared in the second or third levels. In other words, all the libraries have a link in their parent university website, while majority (71\%) of them appear either on the institutional homepage or on its first level.

In brief, the quantitative presence of Sri Lankan university libraries in the cyberspace is quite impressive. Figure 1 summarizes the findings. 


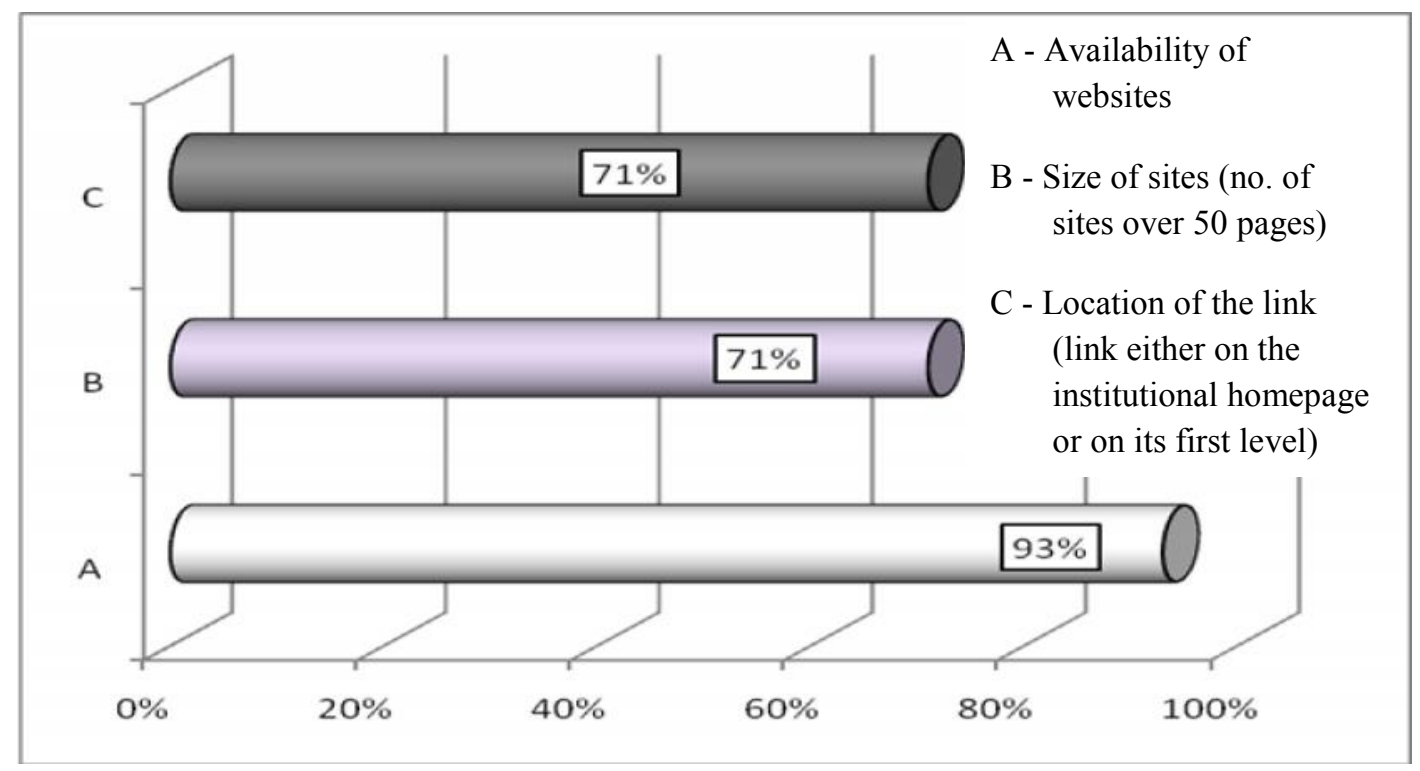

Figure 1: Qualitative Web Presence of Sri Lankan University Libraries

\subsection{Qualitative Web Presence of Libraries}

The quality of websites was measured in terms of content richness and design accuracy.

\subsubsection{Content richness of websites}

The content richness of the websites was determined in term of 10 elements and success level content was calculated in two parameters namely, element-wise and website-wise. See Appendix B for the scales observed in assigning the ranks.

\subsubsection{Success level content - element wise}

The success level content of individual elements was calculated to see the status of availability of each element in the tested library websites. Table 1 presents the results. 
Table 1: Success Level Content - element wise

\begin{tabular}{|l|c|c|c|}
\hline \multicolumn{1}{|c|}{ Content Element } & $\mathbf{n}$ & $\mathbf{N}$ & $\begin{array}{c}\text { Success Level Content } \\
\text { (n/N* } \mathbf{x} \text { 100) }\end{array}$ \\
\hline E-resources & 42 & $5 \times 12=60$ & $70 \%$ \\
\hline Information about printed resources & 51 & $5 \times 12=60$ & $85 \%$ \\
\hline Web-based services & 39 & $5 \times 12=60$ & $65 \%$ \\
\hline Information about in-house services & 52 & $5 \times 12=60$ & $87 \%$ \\
\hline Useful external links & 34 & $5 \times 12=60$ & $57 \%$ \\
\hline About the library & 55 & $5 \times 12=60$ & $70 \%$ \\
\hline Library rules & 42 & $5 \times 12=60$ & $100 \%$ \\
\hline Staff information & 12 & $1 \times 12=12$ & $92 \%$ \\
\hline Contact information & 12 & $1 \times 12=12$ & \\
\hline Opening hours & 11 & $1 \times 12=12$ & \\
\hline
\end{tabular}

$n-$ Total no of marks scored for the element by the tested libraries

$N$-Maximum allocated marks for the element $x$ total no of tested libraries

Out of the 6 high status elements, 2 elements - Staff information and Contact information - are available in all 12 tested library websites. 'About the library' and 'Opening hours' are the next most available content elements among the Sri Lankan University libraries. The 'Useful external links' is the least popular element.

To summarize the findings, the measured elements (10) were grouped into 3 groups as shown in Table 2. 
Table 2: Success Status of Content Elements

\begin{tabular}{|l|c|c|c|}
\hline $\begin{array}{c}\text { Success Status of } \\
\text { Elements }\end{array}$ & Grouping Criteria & No. of Elements & $\%$ \\
\hline High Status & Success Level Content above 80\% & 6 & 60 \\
\hline Medium Status & Success Level Content 60\%-80\% & 3 & 30 \\
\hline Low Status & Success Level Content below 60\% & 1 & 10 \\
\hline
\end{tabular}

Out of the 10 content elements measured, 6 elements scored above $80 \%$ and reached the high status while 3 elements scored between $60 \%$ to $80 \%$ and reached the medium status.

\subsubsection{Success level content - website wise}

The success level content of individual websites was calculated to observe the status of tested websites in terms of content richness. Table 3 presents the results.

Table 3: Success Level Content - website wise

\begin{tabular}{|c|c|c|}
\hline Participants & Content Score (n) & Success Level Content (n/N*100) \\
\hline Website1 & 34 & $89 \%$ \\
\hline Website2 & 34 & $87 \%$ \\
\hline Website3 & 33 & $82 \%$ \\
\hline Website4 & 31 & $89 \%$ \\
\hline Website5 & 34 & $68 \%$ \\
\hline Website6 & 26 & $76 \%$ \\
\hline Website7 & 29 & \\
\hline
\end{tabular}




\begin{tabular}{|c|c|c|}
\hline Website8 & 35 & $92 \%$ \\
\hline Website9 & 31 & $82 \%$ \\
\hline Website10 & 24 & $63 \%$ \\
\hline Website11 & 22 & $58 \%$ \\
\hline Website12 & 17 & $45 \%$ \\
\hline
\end{tabular}

$n$-Content score (total number of marks scored by the library)

$N$-Maximum allocated marks for the 10 elements (38)

The highest content score reported by a library website is 35 (success level content 92\%) while lowest content score reported by a library is 17 (success level content $45 \%)$.

To summarize the findings, the tested websites (12) were grouped into 3 groups as shown in Table 4.

Table 4: Content Richness Level of Websites

\begin{tabular}{|l|l|l|l|}
\hline $\begin{array}{l}\text { Content Richness Level of } \\
\text { websites }\end{array}$ & Grouping Criteria & $\begin{array}{l}\text { No. of Library } \\
\text { Websites }\end{array}$ & $\%$ \\
\hline High Level & Success Level Content above 80\% & 7 & 58 \\
\hline Medium Level & Success Level Content 60\%- 80\% & 3 & 25 \\
\hline Low Level & Success Level Content below 60\% & 2 & 17 \\
\hline
\end{tabular}

Seven libraries have reached the high content richness level and 3 have reached the medium level while 2 remained in the low level.

In a nutshell, the content richness level of the library websites is at a fairly satisfactory level. 


\subsubsection{Design accuracy of the website}

Design accuracy of the websites was determined in terms of 7 design features and success level design was calculated in two parameters namely, design feature-wise and websitewise. See Appendix B for the scales observed in assigning the ranks

\subsubsection{Success level design - design feature wise}

The success level design of the individual design feature was calculated to see the status of availability of each design feature in the tested library websites. Table 5 presents the results.

Table 5: Success Level Design - design feature wise

\begin{tabular}{|l|l|l|l|}
\hline Design Features & $\mathbf{n}$ & $\mathbf{N}$ & $\begin{array}{l}\text { Success Level Design } \\
\text { (n/N x 100) }\end{array}$ \\
\hline $\begin{array}{l}\text { Web accessibility level (WCAG 2.0 } \\
\text { success criteria - Level A) }\end{array}$ & $-13^{*}$ & $3 \times 12=36$ & $-36 \%$ \\
\hline Use of Standard HTML codes & $-25^{*}$ & $3 \times 12=36$ & $-69 \%$ \\
\hline Readability level & 32 & $3 \times 12=36$ & $89 \%$ \\
\hline Site search engine & 6 & $1 \times 12=12$ & $50 \%$ \\
\hline Copyright statement & 11 & $1 \times 12=12$ & $92 \%$ \\
\hline Length of the homepage & 46 & $5 \times 12=60$ & $77 \%$ \\
\hline Last date of update & 15 & $5 \times 12=60$ & $25 \%$ \\
\hline
\end{tabular}

$n-$ Total no of marks scored for the feature by the tested libraries

$N$-Maximum allocated marks for the feature $x$ total no of tested libraries

Two features namely, web accessibility level and use of standard HTML codes reported minus values. 'Last date of update' $(25 \%)$ is also at an unsatisfactory level. However, 'Readability' and 'Copyright statement' reported high success level design values.

* Note: Minus values indicate the presence of number of errors in the measured parameter. 
To summarize the findings, the measured design features (7) were grouped into 3 categories as shown in Table 6.

Table 6: Success Status of Design Features

\begin{tabular}{|l|l|l|l|}
\hline $\begin{array}{l}\text { Success Status of } \\
\text { Features }\end{array}$ & Grouping Criteria & No. of Features & $\%$ \\
\hline High Status & Success Level Design above 80\% & 2 & 29 \\
\hline Medium Status & Success Level Design 60\%-80\% & 1 & 14 \\
\hline Low Status & Success Level Design below 60\% & 4 & 57 \\
\hline
\end{tabular}

Contrast to the status of content elements, status of design features is quite low. The majority of features fall into the category of low status while only 2 features were in the high status.

Figure 2 illustrates the comparison between the success levels of content elements and design features.

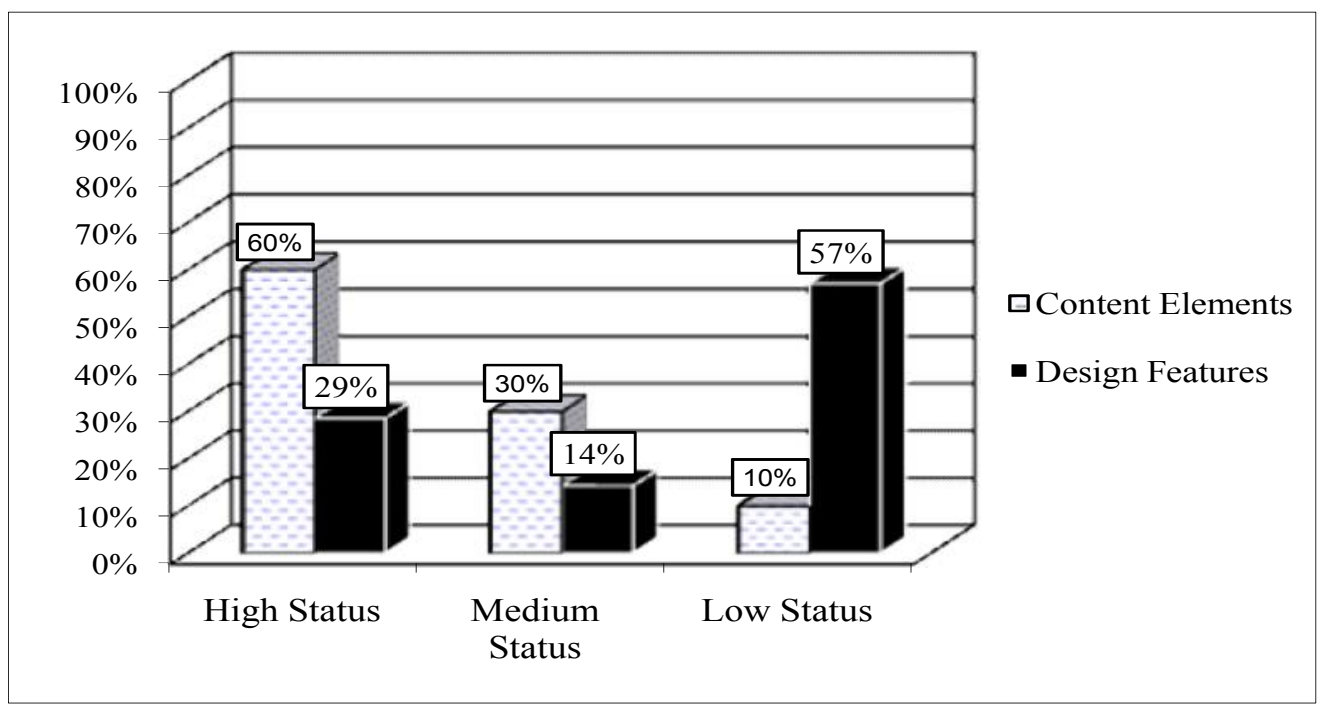

Figure 2: Success Status of Content Elements vs. Success Status of Design Features 
As shown in Figure 1, content elements demonstrate higher percentages both in high status and medium status compare to the percentages of design features in those two statuses.

\subsubsection{Success level design - website wise}

The success level design of individual websites was calculated to observe the status of tested websites in terms design accuracy. Table 7 presents the results.

Table 7: Success Level Design - website wise

\begin{tabular}{|c|c|c|}
\hline Library website & Design score & Success Level Design (n/N*100) \\
\hline Website1 & 6 & $29 \%$ \\
\hline Website2 & 1 & $5 \%$ \\
\hline Website3 & 5 & $24 \%$ \\
\hline Website4 & 6 & $29 \%$ \\
\hline Website5 & 1 & $5 \%$ \\
\hline Website6 & 4 & $19 \%$ \\
\hline Website7 & 15 & $71 \%$ \\
\hline Website8 & 19 & $90 \%$ \\
\hline Website9 & 4 & $19 \%$ \\
\hline Website10 & 4 & $19 \%$ \\
\hline Website11 & 3 & $14 \%$ \\
\hline Website12 & 4 & $19 \%$ \\
\hline
\end{tabular}

$n$-Design score (total number of marks scored by the library)

$N$-Total number of allocated marks for the 7 features (21)

The highest design score reported by a library website is 19 (success level content 90\%) while lowest design score reported by a library is 1 (success level content $5 \%$ ). 
To summarize the findings, the tested websites (12) were grouped into 3 categories as shown in Table 8.

\section{Table 8: Design Accuracy Level of Websites}

\begin{tabular}{|l|c|c|c|}
\hline $\begin{array}{l}\text { Design Accuracy } \\
\text { Level }\end{array}$ & Grouping Criteria & $\begin{array}{c}\text { No. of Library } \\
\text { Websites }\end{array}$ & $\%$ \\
\hline High Level & Success Level Design above 80\% & 1 & 8 \\
\hline Medium Level & Success Level Design 60\%-80\% & 1 & 83 \\
\hline Low Level & Success Level Design below 60\% & 10 & 83 \\
\hline
\end{tabular}

It is clear that the design accuracy level of the websites of Sri Lankan university libraries is literally poor. Only 2 libraries managed to reach the high level and the medium level, while 10 libraries remain in the low level.

Figure 3 illustrates the comparison between the content richness level and design accuracy level of websites.

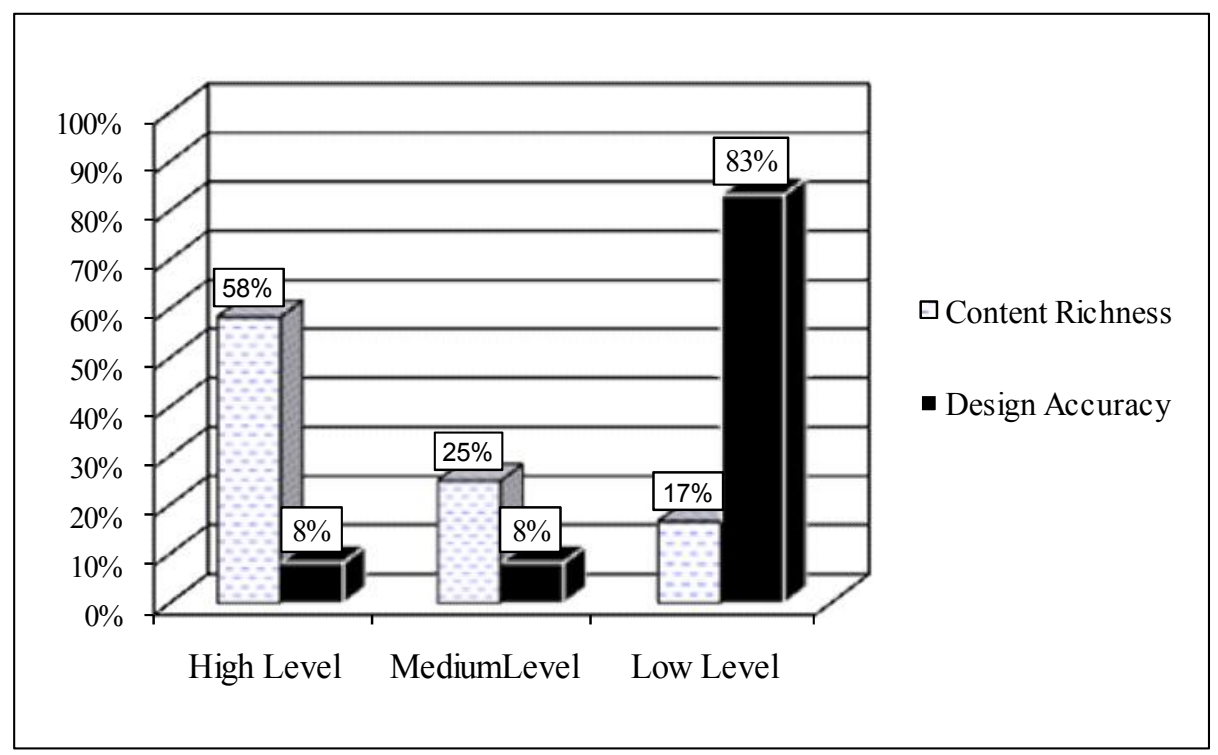

Figure 3: Content Richness Level of Websites vs. Design Accuracy Level of Websites

As shown in figure 3 , there were $58 \%$ of websites in the high status when measured in terms of content richness while only $8 \%$ of those websites reached the high status when 
measured in terms of design accuracy. Meanwhile, majority of library websites (83\%) were in the low status in the design accuracy perspective.

\section{Concluding Remarks}

Findings of this study draw attention towards certain important factors and carry certain helpful messages to the library professionals. All the libraries, except a recently established university library, have marked their presence gracefully in the cyberspace, with majority of sites (86\%) exceeding 50 pages. The content richness of the library websites is also at a satisfactory level, though, room for improvement is substantial. When comparing the library websites that have achieved high content scores with those that have gained low content scores, it appears that success does not depend on the availability of expensive e-resources or maintaining web services based on sophisticated web tools or software systems. Almost all the libraries in the high content richness level demonstrate an effective use of free and open source software tools and open access resources in developing their web-based services and in designing information products.

The design accuracy level of the Sri Lankan university library websites is totally a different story of the content richness level. The main reason behind this discouraging situation seems to be either the lack of awareness or absence of interest towards application of accessibility guidelines and use of standard HTML codes. Both these features scored minus values and reduced the success level design percentage of all the tested websites significantly. Another factor that should be highlighted is the weakness shown in displaying the last date of update. Three websites did not display the last update date at all and 3 websites displayed a date a year or more ago (over 2 years in two cases) as their last update date. This may be due to the failure in updating the date only or failure in updating the site itself from the date mentioned. Either way, displaying a date that is so old is a huge drawback under the international standards and a challenge to the validity of the content of the site. 
Enriching the web content is a time consuming effort and needs fair amount of intellectual contribution. Conversely, as explained in the introduction, correcting the accessibility errors and fixing the HTML codes is quite simple and straight forward. There are more than enough open source tools and web services that are able to highlight the error/s in black and white and capable of suggesting corrective measures. Hence, it is clear that the design accuracy level of tested library websites can be easily raised with a little bit more effort from the part of the librarians.

Another important point, that author wishes to bring to the notice before concluding, is that the results presented here are generated based on a simple tool that covers only the basic areas through 17 items. Hence, even the sites that have attained the high level may also have a distance to walk to reach the international benchmarks. However, the author strongly believes that Sri Lankan librarians are quite capable to go on par with their international colleagues from developed countries, if appropriate training opportunities and adequate resources are provided.

\section{References}

Aharony, N. (2012). An analysis of American academic libraries' websites: 2000- 2010. Electronic Library, 30 (8), 764-776.

Astani, M. \& Elhindi, M.A. (2008). An empirical study of university websites. Retrieved from www.iacis.org/iis/2008_iis/pdf/S2008_1077.pdf

Chen, Y., Germain, C.A. \& Yang, H. (2009). An exploration into the practices of library web usability in ARL academic libraries. Journal of the American Society for Information Science and Technology, 60, 953-68.

Foley, A. (2003). Integrating accessible design into the educational web design. Meridian: A Middle School Computer Technologies Journal, 6 (1). Retrieved from http://www.ncsu.edu/meridian/win2003/accessibility/index.html

Golub, K. \& Lazic, N. (2001). Accessibility of public library web sites. Libraries in the digital age, Dubrovnik: Integrating information seeking and information services practice and research. Retrieved from http://www.it.lth.se/koraljka/Lund/publ/GolubLazicLIDA2002-eng.pdf 
Irvall, B.\& Nielsen, G.S. (2005). Access to libraries for persons with disabilities: checklist (IFLA professional report 89). Retrieved from http://archive.ifla.org/VII/s9/nd1/iflapr89e.pdf

Jasek, C. (2007). How to design library Websites to maximize usability. Retrieved from http://libraryconnect.elsevier.com/lcp/0502/lcp0502.pdf

Kaba, A. (2011). Marketing information resources and services on the web: current status of academic libraries in the United Arab Emirates. Information Development, 27(1) 5865.

Kirkpatrick, C.H. (2003). Getting two for the price of one: accessibility and usability. Computers in Libraries, 23 (1), 26-37.

Madhusudhan, M. \& Nagabhushanam, V. (2012). Web-based library services in university libraries in India: an analysis of librarians' perspective. Electronic Library, 30 (5), 569588.

Manuel, S., Dearnley, J. \& Walton, G. (2010). Strategic development of UK academic library websites: a survey of East Midlands university libraries. Journal of Librarianship and Information Science, 42(2) 147-155.

Polanka, S. \& O'Gorman, J. (2001). Guidelines for creating accessible library web pages. Internet Reference Services Quarterly, 5 (3), 51-57.

Poll, R. (2007). Evaluating the library websites: statistical and quality measures. Retrieved from www.ifla.org.sg/IV/ifla73/papers/074-Poll-en.pdf

Sloan, D. (2004). How to uncover a web site's accessibility barriers. Retrieved from http://www.dmag.org.uk/resources/design_articles/howtojudge.asp

Vasishta, S. (2013). Dissemination of electronic journals: a content analysis of the library websites of technical university libraries in North India. Electronic Library, 31(3), 278289.

Wickramanayake, L. (2012). Instruction and help services in the academic library websites and web pages in Sri Lanka: a content analysis. Electronic Library, 30 (3), 377-389.

Wijayaratne, A. \& Amrasekara, R. (2011). Readiness in academic libraries to serve the differently-abled patrons. Conference proceedings - 8th National Conference on Library and Information Science on Harnessing information for Socio-economic Development, Colombo, Sri Lanka, 51-59. 
Appendix A

\section{Summary of WCAG 2.0 Guidelines}

1. Perceivable - Information and user interface components must be presentable to users in ways they can perceive

1.1 Provide text alternatives for any non-text content so that it can be changed into other forms people need, such as large print, braille, speech, symbols or simpler language.

1.2 Provide alternatives for time-based media.

1.3 Create content that can be presented in different ways (for example simpler layout) without losing information or structure.

1.4 Make it easier for users to see and hear content including separating foreground from background.

2. Operable - User interface components and navigation must be operable

2.1 Make all functionality available from a keyboard.

2.2 Provide users enough time to read and use content.

2.3 Do not design content in a way that is known to cause seizures.

2.4 Provide ways to help users navigate, find content, and determine where they are.

3. Understandable - Information and the operation of user interface must be understandable

3.1 Make text content readable and understandable.

3.2 Make Web pages appear and operate in predictable ways.

3.3 Help users avoid and correct mistakes.

4. Robust - Content must be robust enough that it can be interpreted reliably by a wide variety of user agents, including assistive technologies.

4.1 Maximize compatibility with current and future user agents, including assistive technologies.

(Web Accessibility Initiative WAI of the Worldwide Web Consortium) 
Evaluative Instrument - qualitative web presence of academic libraries

\begin{tabular}{|c|c|c|c|}
\hline Content Elements & Score & Design Features & Score \\
\hline \multicolumn{2}{|l|}{ E-resources } & \multicolumn{2}{|l|}{$\begin{array}{l}\text { Web accessibility level (WCAG } 2.0 \text { success } \\
\text { criteria - Level A)* }\end{array}$} \\
\hline Level of availability & $1-5$ & Zero errors & 3 \\
\hline Absence & 0 & 1-5 errors & -1 \\
\hline \multicolumn{2}{|c|}{ Information about printed resources } & 6-10 errors & -2 \\
\hline Level of availability & $1-5$ & More than 10 errors & -3 \\
\hline Absence & 0 & \multicolumn{2}{|l|}{ Use of standard HTML codes* } \\
\hline \multicolumn{2}{|l|}{ Web-based services } & Zero errors & 3 \\
\hline Level of availability & $1-5$ & 1-10 errors & -1 \\
\hline Absence & 0 & 11-20 errors & -2 \\
\hline \multicolumn{2}{|c|}{ Information about in-house services } & More than 20 errors & -3 \\
\hline Level of availability & $1-5$ & \multicolumn{2}{|l|}{ Readability level } \\
\hline Absence & 0 & Readability score less than 15 & 3 \\
\hline \multicolumn{2}{|l|}{ Useful external links } & Readability score $15-17$ & 2 \\
\hline Level of availability & $1-5$ & Readability score above 17 & 0 \\
\hline Absence & 0 & \multicolumn{2}{|l|}{ Site search engine } \\
\hline \multicolumn{2}{|l|}{ About the library } & Presence & 1 \\
\hline Level of availability & $1-5$ & Absence & 0 \\
\hline Absence & 0 & Copyright statement & \\
\hline
\end{tabular}


Journal of the University Librarians Association of Sri Lanka, Vol.17, Issue 1, January 2013

\begin{tabular}{|c|c|c|c|}
\hline Library rules & & Presence & 1 \\
\hline Level of availability & $1-5$ & Absence & 0 \\
\hline Absence & 0 & \multicolumn{2}{|l|}{ Length of the homepage } \\
\hline \multicolumn{2}{|l|}{ Staff information } & 1 page & 5 \\
\hline Presence & 1 & 1.5 to 2 pages & 3 \\
\hline Absence & 0 & More than 2 pages & 0 \\
\hline \multicolumn{2}{|l|}{ Contact information } & \multicolumn{2}{|l|}{ Last date of update } \\
\hline Presence & 1 & Less than 1 week & 5 \\
\hline Absence & 0 & 1-4 weeks & 3 \\
\hline \multicolumn{2}{|l|}{ Opening hours } & 1-2 months & 2 \\
\hline Presence & 1 & 2-12 months & 1 \\
\hline Absence & 0 & More than $1 y r$ or no date & 0 \\
\hline
\end{tabular}

* Note: The scales for the two design features include minus values (+3 to -3$)$ since the presence of number of errors in these 2 areas cause negative impact on design accuracy of the website. 
Appendix C

\section{List of Library Websites}

University of Colombo

http://www.lib.cmb.ac.lk/

University of Peradeniya

http://www.lib.pdn.ac.lk/

University of Sri Jayewardenepura

http://www.lib.sjp.ac.lk/
Rajarata University of Sri Lanka

http://www.rjt.ac.lk/maiin_library/main_Lib.html

Sabaragamuwa University of Sri Lanka

http://www.sab.ac.lk/library/index.htm

Wayamba University of Sri Lanka

http://libsys.wyb.ac.lk/

University of Kelaniya

http://www.kln.ac.lk/units/library/

University of the Visual \& Performing Arts

http://www.vpa.ac.lk/index.php?option=com_content\&view=article\&id=57\&ltemid=65

University of Moratuwa

http://www.lib.mrt.ac.lk/

University of Jaffna

http://www.jfn.ac.Ik/library/index.htm

University of Ruhuna

http://www.lib.ruh.ac.lk/

The Open University of Sri Lanka

http://lib.ou.ac.lk/

Eastern University, Sri Lanka

http://www.esn.ac.lk/Library/Index.htm

South Eastern University of Sri Lanka

http://www.seu.ac.Ik/library/libhome.ht

$\mathrm{ml}$ 